\title{
Effects of Brain Amyloid Deposition and Reduced Glucose Metabolism on the Default Mode of Brain Function in Normal Aging
}

\author{
Mitsuru Kikuchi, ${ }^{1}$ Tetsu Hirosawa, ${ }^{2}$ Masamichi Yokokura, ${ }^{3}$ Shunsuke Yagi, ${ }^{3}$ Norio Mori, ${ }^{3}$ Etsuji Yoshikawa, ${ }^{6}$ \\ Yujiro Yoshihara, ${ }^{3}$ Genichi Sugihara, ${ }^{3}$ Kiyokazu Takebayashi, ${ }^{3}$ Yasuhide Iwata, ${ }^{3}$ Katsuaki Suzuki, ${ }^{3}$ \\ Kazuhiko Nakamura, ${ }^{3}$ Takatoshi Ueki, ${ }^{5}$ Yoshio Minabe, ${ }^{2}$ and Yasuomi Ouchi ${ }^{4}$ \\ ${ }^{1}$ Research Center for Child Mental Development and ${ }^{2}$ Department of Psychiatry and Neurobiology, Graduate School of Medical Science, Kanazawa University, \\ Kanazawa 920-8641, Japan, ${ }^{3}$ Department of Psychiatry and Neurology, ${ }^{4}$ Medical Photonics Research Center, and ${ }^{5}$ Department of Neuroanatomy, Hamamatsu \\ University School of Medicine, Hamamatsu 431-3192, Japan, and ${ }^{6}$ Central Research Laboratory, Hamamatsu Photonics K.K., Hamamatsu 434-8601, Japan
}

Brain $\beta$-amyloid $(\mathrm{A} \beta$ ) deposition during normal aging is highlighted as an initial pathogenetic event in the development of Alzheimer's disease. Many recent brain imaging studies have focused on areas deactivated during cognitive tasks [the default mode network (DMN), i.e., medial frontal gyrus/anterior cingulate cortex and precuneus/posterior cingulate cortex], where the strength of functional coordination was more or less affected by cerebral $\mathrm{A} \beta$ deposits. In the present positron emission tomography study, to investigate whether regional glucose metabolic alterations and $\mathrm{A} \beta$ deposits seen in nondemented elderly human subjects $(n=22)$ are of pathophysiological importance in changes of brain hemodynamic coordination in DMN during normal aging, we measured cerebral glucose metabolism with $\left[{ }^{18} \mathrm{~F}\right] \mathrm{FDG}, \mathrm{A} \beta$ deposits with $\left[{ }^{11} \mathrm{C}\right] \mathrm{PIB}$, and regional cerebral blood flow during control and working memory tasks by $\mathrm{H}_{2}{ }^{15} \mathrm{O}$ on the same day. Data were analyzed using both region of interest and statistical parametric mapping. Our results indicated that the amount of $\mathrm{A} \beta$ deposits was negatively correlated with hemodynamic similarity between medial frontal and medial posterior regions, and the lower similarity was associated with poorer working memory performance. In contrast, brain glucose metabolism was not related to this medial hemodynamic similarity. These findings suggest that traceable $\mathrm{A} \beta$ deposition, but not glucose hypometabolism, in the brain plays an important role in occurrence of neuronal discoordination in DMN along with poor working memory in healthy elderly people.

\section{Introduction}

Accumulated evidence obtained by functional brain imaging has revealed two dominant domains that act in opposite ways to each other. One set of brain areas shows increases in activity, while the other set of areas shows decreases in activity during performance of a wide range of different types of cognitive task (Fox et al., 2005). The former set of brain areas includes the dorsolateral prefrontal cortex (DLPFC) and the precentral and inferior parietal cortices (Cabeza and Nyberg, 2000; Owen et al., 2005). The latter set of brain areas includes the precuneus and posterior cingulate cortex (preC/PCC), and a medial frontal region includ-

Received May 20, 2011; accepted June 14, 2011.

Author contributions: M.K., N.M., and Y.O. designed research; M.K., T.H., M.Y., S.Y., E.Y., Y.Y., G.S., K.T., Y.I., K.S., K.N., T.U., Y.M., and Y.O. performed research; M.K. contributed unpublished reagents/analytic tools; M.K., T.H., E.Y., T.U., and Y.O. analyzed data; M.K. and Y.O. wrote the paper.

This work was supported by the Ishikawa High-Tech Sensing Cluster Grant (Knowledge Cluster Initiative from the Japanese Ministry of Education, Culture, Sports, Science, and Technology), New Energy and Industrial Technology Development Organization, and the Takeda Science Foundation. We thank Toshihiko Kanno, Yasuo Tanizaki (Hamamatsu Medical Center), Masami Futatsubashi (Hamamatsu Photonics KK), and Yutaka Naito (Japan Environment Research Corporation) for their support.

The authors declare no competing financial interests.

Correspondence should be addressed to Dr. Yasuomi Ouchi, Department of Biofunctional Imaging, Medical Photonics Research Center, Hamamatsu University School of Medicine, 1-20-1 Handayama, Higashi-ku, Hamamatsu 431-3192, Japan. E-mail: ouchi@hama-med.ac.jp.

DOI:10.1523/JNEUROSCI.2535-11.2011

Copyright $\odot 2011$ the authors $\quad 0270-6474 / 11 / 3111193-07 \$ 15.00 / 0$ ing parts of medial frontal gyrus and ventral anterior cingulate cortex (MFG/vACC) (Raichle, 1998; Gusnard and Raichle, 2001; Mazoyer et al., 2001; Simpson et al., 2001a; Fox et al., 2005). These latter task-negative responses have been proposed as the default mode of brain function (Simpson et al., 2001a), and coactivation in a distributed network [i.e., the default mode network $(\mathrm{DMN})]$ in these cortical regions has been revealed (Greicius et al., 2003). Specifically, the posterior part of the DMN (i.e., precuneus) has been recognized as the region with early changes in glucose metabolism (Silverman et al., 2001; Drzezga et al., 2003) as well as A $\beta$ deposition (Mintun et al., 2006) in Alzheimer's disease $(\mathrm{AD})$. Recent imaging studies also showed that the $\mathrm{DMN}$ function was impaired in $\mathrm{AD}$ patients and altered in healthy elderly people by some degree of $\mathrm{A} \beta$ deposition (Greicius et al., 2004; Supekar et al., 2008; Hedden et al., 2009; Sperling et al., 2009; Zhang et al., 2009; Sheline et al., 2010). Therefore we hypothesized that, even in the healthy older individuals, altered default mode of brain function is associated with some degree of amyloid pathology, of reduction in glucose metabolism, and of deterioration of cognitive performance, which may be central to aging effect on slowness of thoughts in the elderly. However, no previous study has demonstrated them all in the same subjects. The main purpose of the present study was to examine whether the DMN measured by the steady-state brain hemodynamic configuration is relevant to the cognitive decline, 
glucose hypometabolism, and amyloid burden under normal aging. The advantage of the present study was that measurement of these biological parameters in the same subjects on the same day allowed us to compare the default mode of brain function with amount of $\mathrm{A} \beta$ deposit by $\left[{ }^{11} \mathrm{C}\right]$ Pittsburgh compound B (PIB)positron emission tomography (PET) and with glucose metabolism by $\left[{ }^{18} \mathrm{~F}\right]$ fluorodeoxyglucose (FDG)-PET directly. To evaluate the DMN under steady-state hemodynamic configurations during various cognitive conditions (the mean of phasic variations), $\mathrm{H}_{2}{ }^{15} \mathrm{O}$-PET was used for assessment of steady-state cerebral blood flow.

\section{Materials and Methods}

Participants. We examined 22 healthy elderly subjects ( 9 men and 13 women; mean age $68.0 \pm 7.28$ years) (Table 1 ). None of the subjects had any personal or family history of psychiatric or neurological diseases. The exclusion criteria were (1) dysfunction or difficulty in independence in their daily lives, or loss of social interaction in their community, as assessed by Clinical Dementia Rating (CDR) (Morris, 1993) $\geq 0.5$ or Functional Assessment Staging of Alzheimer's Disease (FAST) (Reisberg, 1986) $\geq 2$; (2) presence of significant white matter microvascular changes on magnetic resonance imaging (MRI) over and above a few scattered lacunas compatible with normal aging; (3) drinking large amounts of alcohol regularly or smoking; (4) taking any medication for at least 8 weeks before the examination; and (5) untreated hypertension or diabetes. The present study was approved by the Ethics Committee of Hamamatsu Medical Center, and written informed consent was obtained from all participants before enrollment.

MRI scanning. All participants underwent threedimensional MRI just before PET measurement. Here, a static magnet (0.3 T MRP7000AD; Hitachi) was used in three-dimensional mode (Ouchi et al., 2001).

Working memory task. Visual tasks were presented on a liquid crystal screen in front of subjects during PET scanning. One type of resting control condition and two types of working memory task were used; as shown in Figure 1, one was the simple visual working memory task (WM task) and the other was the visual working memory with mental rotation (RWM task).

Regional cerebral blood flow measurement using PET scan during working memory task. We used a high-resolution brain PET scanner (SHR12000; Hamamatsu Photonics K.K.) (Ouchi et al., 1999). After head fixation using a thermoplastic face mask and a $10 \mathrm{~min}$ transmission scan, we performed quantitative measurement of regional cerebral blood flow $(\mathrm{rCBF})$ in the conventional manner (Herscovitch et al., 1983; Ouchi et al., 2001). Nine 1 min PET scans for rCBF were performed under various conditions, as shown in Figure $1 \mathrm{~B}$. The dose of $\mathrm{H}_{2}{ }^{15} \mathrm{O}$ injected was $4 \mathrm{MBq} / \mathrm{kg}$ per scan.

Image data acquisition. After measurement of rCBF during working memory, with a rest period of $1 \mathrm{~h}, 40$ serial PET scans (time frames: $12 \times$ $10,18 \times 60$, and $10 \times 300 \mathrm{~s}$ ) were performed for $70 \mathrm{~min}$ after injection of $5 \mathrm{MBq}\left[{ }^{11} \mathrm{C}\right] \mathrm{PIB} / \mathrm{kg}$. Later, a static $15 \mathrm{~min}$ PET scan was performed 45 min after injection of $1.2 \mathrm{MBq} / \mathrm{kg}$ dose of $\left[{ }^{18} \mathrm{~F}\right] \mathrm{FDG}$.

Image data processing. To evaluate $\mathrm{rCBF}, \mathrm{H}_{2}{ }^{15} \mathrm{O}$-PET images from each participant were individually adjusted for mean image (normalized rCBF) (Ouchi et al., 2001). To evaluate glucose metabolism, a semiquantitative ratio index of $\left[{ }^{18} \mathrm{~F}\right] \mathrm{FDG}$ was calculated as standardized uptake value ratio (SUVR) (Ouchi et al., 2009). To evaluate $A \beta$ accumulation, a semiquantitative ratio index of $\left[{ }^{11} \mathrm{C}\right]$ PIB binding potentials was estimated as SUVR (Yokokura et al., 2011).

ROI analysis. PET images using $\mathrm{H}_{2}{ }^{15} \mathrm{O}$ were realigned, and all PET images, including $\left[{ }^{18} \mathrm{~F}\right] \mathrm{FDG}$-SUVR and $\left[{ }^{11} \mathrm{C}\right] \mathrm{PIB}$-SUVR images, were
Table 1. Demographic characteristics of all subjects

\begin{tabular}{lc}
\hline Group & Healthy subjects \\
\hline Total number & 22 \\
Male/female & $9 / 13$ \\
Age (years) & $68.0(57-81)$ \\
Education (years) & $10.7(8-16)$ \\
CDR & $0(0)$ \\
FAST & $1(1)$ \\
MMSE score & $28.8(26-30)$ \\
Cubic copying test & \\
$\quad$ Point of connection & $8(8)^{a}$ \\
$\quad$ Plane-drawing errors & $0(0)^{b}$ \\
Lexical fluency & $3(3)^{c}$ \\
Correct answer for WM and RWM test (\%) & $94.4(86.7-100.0)^{d}$ \\
\hline
\end{tabular}

MMSE, Mini-Mental State Examination. ${ }^{a}$ Eight points represents a perfect score (Maeshima et al., 1997). ${ }^{b}$ Zero points represents a perfect score (Maeshima et al., 1997). Three points represents a perfect score (Frontal Assessment Battery subtest) (Dubois et al., 2000). ${ }^{d}$ One hundred percent represents a perfect score. Except for the first two rows, values are given as mean (range).

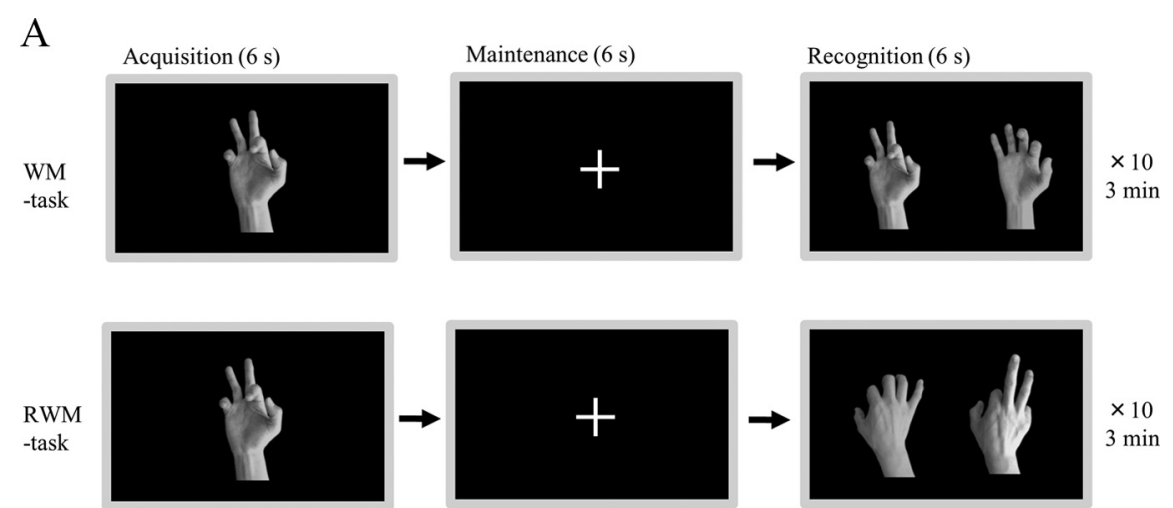

B

Figure 1. Task paradigm. $\boldsymbol{A}$, Subjects performed two types of working memory task; one was a simple visual WM task and the palm side (acquisition) to the rear (recognition). For the resting control condition (Con), subjects were asked to look at a cross mark centered in the screen. To avoid drowsiness under control conditions, subjects were instructed to press a button in the right or left hand every 18 s. B, Each condition continued for $3 \mathrm{~min}$ and each interval lasted for $7 \mathrm{~min}$ with the eyes closed (black square).

spatially normalized into the Montreal Neurological Institute (MNI) coordinate system using $\left[{ }^{18} \mathrm{~F}\right] \mathrm{FDG}-\mathrm{PET}$ template for $\mathrm{H}_{2}{ }^{15} \mathrm{O}$ and $\left[{ }^{18} \mathrm{~F}\right] \mathrm{FDG}$ images and early summation $\left[{ }^{11} \mathrm{C}\right] \mathrm{PIB}$ PET template for $\left[{ }^{11} \mathrm{C}\right] \mathrm{PIB}$ images to calculate the warping parameters (Nelissen et al., 2007), and smoothed with a $8 \times 8 \times 8 \mathrm{~mm}$ Gaussian kernel using SPM8 (Wellcome Department of Cognitive Neurology, http://www.fil.ion.ucl. ac.uk/spm/software/spm8/). The use of a thermoplastic face mask and three-dimensional laser markers enabled us to keep the subjects' heads fixed in the same position during a series of all PET measurements $(\mathrm{Ou}-$ chi et al., 2006). For $\mathrm{H}_{2}{ }^{15} \mathrm{O}$ and $\left[{ }^{18} \mathrm{~F}\right]$ FDG images, proportional scaling was used to correct for within-session variations in global signals for each adjusted mean image. Regional data for CBF, $\left[{ }^{11} \mathrm{C}\right] \mathrm{PIB}$ index, and $\left[{ }^{18} \mathrm{~F}\right] \mathrm{FDG}$ index were determined automatically for each participant using MarsBaR, which provided us with a sophisticated template for regions of interest (ROIs) on statistical parametric mapping (SPM) normalized images [MARSeille Boîte À Région d'Intérêt (Brett et al., 2002)]. The details of this ROI procedure have been reported previously (Tzourio-Mazoyer et al., 2002).

Similarity index in the default mode network. To evaluate functional coupling between MFG/vACC and preC/PCC (or level of frontoposterior disengagement in DMN), we used Spearman's rank correlation coefficient as a similarity index, in which a higher value of this index denoted a higher functional engagement in DMN. We used this coeffi- 
A

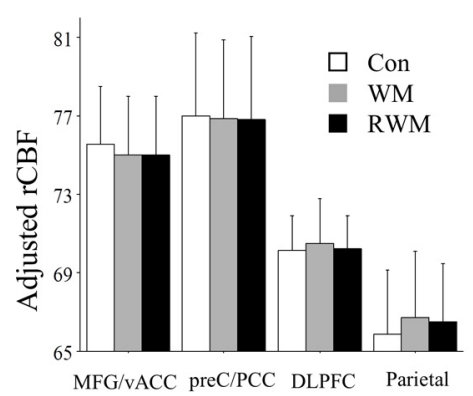

B task-positive regions

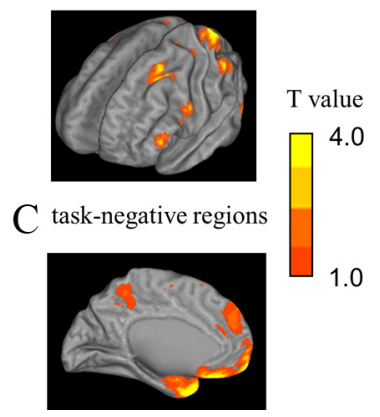

Figure 2. $\quad A$, Results of ROl analyses. Three-way ANCOVA showed a significant interaction between region and condition effects (Table 2). This interaction was due to the inverse hemodynamic responses to memory task between ROIs (i.e., medial vs lateral ROIs). Error bars indicate 1 SD. $\boldsymbol{B}$, Exploratory SPM analyses ( $p<0.001$, uncorrected). Significant elevation of $\mathrm{rCBF}$ in DLPFC and parietal and occipital cortices during memory conditions (WM and RWM tasks) as compared with control conditions. C, Significant reduction of rCBF in MFG, preC, and occipital cortex during memory conditions (WM and RWM tasks) as compared with control conditions. Con, Control condition.

cient because it is available without knowledge of the joint probability distribution of these two regions.

Statistics for ROI analysis. For the rCBF variable, three-way analysis of covariance (ANCOVA) was performed (ROI $\times$ condition $\times$ gender). Two factors were within subjects for region effect (MFG/vACC vs preC/ PCC vs DLPFC vs parietal cortex) and condition effect (control vs WM task vs RWM task). One factor was between subjects for gender effect (male vs female). To remove the effect of age, we defined age as a covariate. Statistical significance was defined as $p<0.05$. Relationships between dependent variables (i.e., $\left[{ }^{11} \mathrm{C}\right] \mathrm{PIB}$ or $\left[{ }^{18} \mathrm{~F}\right] \mathrm{FDG}$ index from 11 $\mathrm{ROI}$ ) and independent variables (hemodynamic similarity index, working memory performance, or age) were assessed using Spearman's rank correlation coefficient. Statistical significance was defined as $p<0.0045$ because of multiple comparisons (11 ROIs). In addition, the effects of age on these independent variables were assessed using Spearman's rank correlation coefficient, and gender differences in these independent variables were assessed using Mann-Whitney $U$ test. Statistical significance was defined as $p<0.05$.

Statistics for voxelwise analysis. SPM8 was used for voxelwise analysis. All $\left[{ }^{15} \mathrm{O}\right] \mathrm{rCBF},\left[{ }^{11} \mathrm{C}\right] \mathrm{PIB}-S U V R$, and $\left[{ }^{18} \mathrm{~F}\right] \mathrm{FDG}$-SUVR parametric images were first normalized to the MNI space and smoothed with an isotropic Gaussian kernel of $8 \mathrm{~mm}$ (same method with ROI analysis). The between-condition comparisons for rCBF were performed using the flexible factorial model with a statistical threshold set at $p=0.001$ uncorrected for peak height. Confounding factors of age and gender were included in the model. Voxel-based correlations were computed between rCBF similarity index and $\left[{ }^{11} \mathrm{C}\right] \mathrm{PIB}-$ SUVR and $\left[{ }^{18} \mathrm{~F}\right]$ FDG-SUVR parametric images using the multiple regression model with the statistical threshold set at $p=0.001$ uncorrected for peak height. Confounding factors of age and gender were also included in the model.

\section{Results}

\section{Changes in regional cerebral blood flow}

rCBF was estimated in the brain regions that were a priori considered important in DMN (MFG/vACC and preC/PCC as task-negative regions, DLPFC and parietal lobes as task-positive regions) for each participant. Three-way ANCOVA showed a significant interaction effect between ROI and condition $(F=2.28 ; p=0.041)$ (Fig. $2 A$, Table 2). As shown in Figure $2 A$, this interaction was due to the inverse hemodynamic responses to memory task between ROIs (especially medial vs lateral ROIs). Whole-brain SPM analysis revealed significant elevation of $\mathrm{rCBF}$ in superior, middle, and inferior frontal gyri, superior parietal lobules, middle and inferior occipital gyri, and fusiform gyrus (Fig. 2 B), and significant
Table 2. Three-way ANCOVA for rCBF hemodynamics

\begin{tabular}{|c|c|c|c|c|c|c|c|c|}
\hline & \multicolumn{2}{|c|}{ Region effect } & \multicolumn{2}{|c|}{ Condition effect } & \multicolumn{2}{|c|}{ Gender effect } & \multicolumn{2}{|c|}{$\begin{array}{l}\text { Interaction: } \\
\text { region } \times \text { condition }\end{array}$} \\
\hline & Fvalue & $p$ value & $F$ value & $p$ value & $F$ value & $p$ value & $F$ value & $p$ value \\
\hline $\mathrm{rCBF}$ & 5.17 & 0.003 & 3.31 & 0.047 & 0.51 & n.s. & 2.28 & 0.041 \\
\hline
\end{tabular}

We used the ANCOVA in order to remove the effect of a covariate (age). Two factors for within subject: region effect, $\mathrm{MFG} / \mathrm{vACC}$ versus preC/PCC versus DLPFC versus parietal cortex; condition effect, control versus WM-task versus RWM-task. One factor for between subjects: gender effect, male versus female. Covariance: age. n.s., № significance.

reduction in superior, medial, and inferior frontal gyri, uncus, precentral gyrus, superior and middle temporal gyri, angular gyrus, and precuneus (Fig. 2C) during working memory as compared with control conditions.

\section{Correlations between regional $\left[{ }^{11} \mathrm{C}\right] \mathrm{PIB}-\mathrm{SUVR}$ and}

hemodynamic similarity index

Figure $4 A$ denotes Spearman's rank correlation between regional $\left[{ }^{11} \mathrm{C}\right]$ PIB-SUVR (separating the whole brain into 11 regions) and hemodynamic similarity index. PIB-SUVR in the whole cerebral cortex, MFG/vACC, and middle temporal and inferior temporal cortices showed a negative correlation with the hemodynamic similarity in DMN $(\rho=-0.640, p=0.0034$ for the whole brain as shown in Fig. 3A). Whole-brain SPM correlation analysis showed that PIB uptake in the cingulate gyrus, parahippocampal gyrus, fusiform gyrus, cuneus, insula, and lentiform nucleus were correlated negatively with the similarity index (Table 3, Fig. 4B).

\section{Correlations between regional $\left[{ }^{18}\right.$ F]FDG-SUVR and hemodynamic similarity index}

Although ROI analysis failed to demonstrate any correlation between adjusted regional FDG-SUVR and hemodynamic similarity index (Fig. 5A), we continued to perform voxel-based analysis. As shown in Table 3 and Figure 5B, relatively higher FDG-SUVR in the temporooccipital region (outside the medial DMN region) was associated with higher similarity index.

\section{Correlations between working memory performance and} hemodynamic similarity index, regional $\left[{ }^{11} \mathrm{C}\right] \mathrm{PIB}-\mathrm{SUVR}$, or regional $\left[{ }^{18} \mathrm{~F}\right]$ FDG-SUVR

Spearman's rank correlation coefficient showed the number of correct answers correlated positively with the similarity index in $\operatorname{DMN}(\rho=0.646, p=0.0031)$ (Fig. $3 B$ ), and negatively with the PIB-SUVR in middle temporal cortices (Fig. $4 A$ ). There was no significant correlation between cognitive performance and regional FDG-SUVR (Fig. 5A).

\section{Effect of age on hemodynamic similarity index, working} memory performance, regional $\left[{ }^{11} \mathrm{C}\right] \mathrm{PIB}-S U V R$, or regional $\left[{ }^{18}\right.$ F]FDG-SUVR

Spearman's rank correlation coefficient showed no significant correlation between age and similarity index $(\rho=0.274, p>$ $0.05)$, working memory performance $(\rho=0.002, p>0.05)$, or regional [11C]PIB-SUVR in all 11 ROIs $(p>0.0045)$ (Fig. $4 A)$. There was no brain region but superior temporal cortex, in which [18F]FDG-SUVR was significantly correlated with age $(\rho=-0.627, p=0.0040)$.

Effect of gender difference on age, hemodynamic similarity index, and working memory performance

Mann-Whitney $U$ test failed to demonstrate any significant gender differences for age $(U=52.5, p>0.05)$, similarity 
A Hemodynamic similarity with seed region (MFG/vACC)
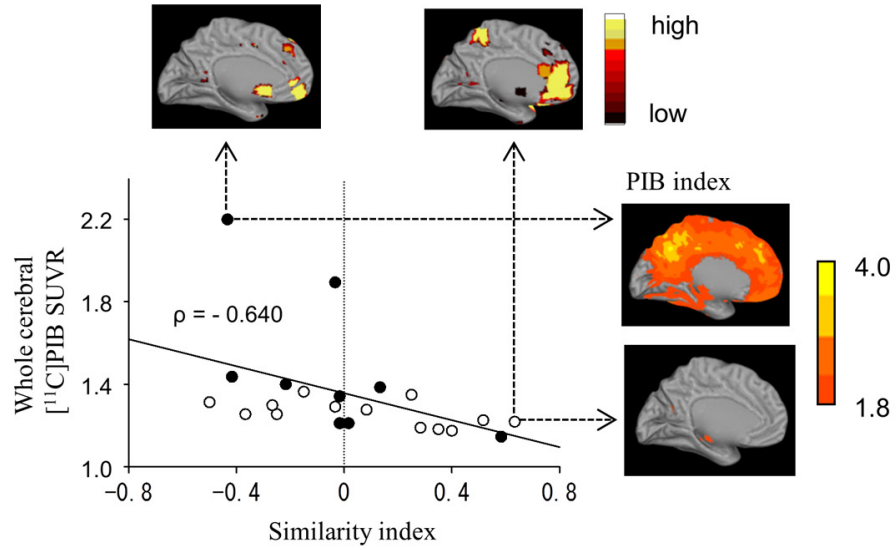

B

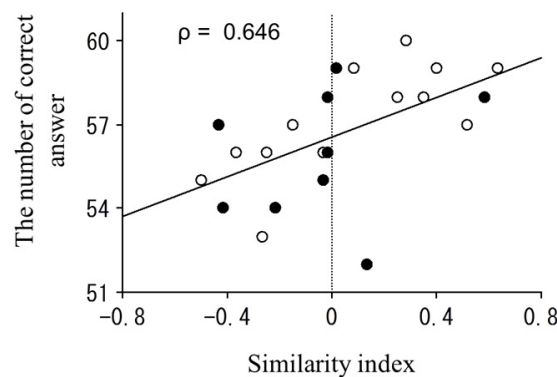

Figure 3. $A,\left[{ }^{11} \mathrm{C}\right] \mathrm{PIB}$-SUVR in the whole cerebral cortex was correlated negatively with the similarity index $(\rho=-0.640, p=0.0034)$. Representative images for opposite changes between $\left[{ }^{11} \mathrm{C}\right] \mathrm{PIB}$ index and hemodynamic similarity were shown in two subjects. A subject (top left) with the higher PIB index shows the lower hemodynamic similarity in preC/PCC with seed region (MFG/vACC), whereas the other subject (bottom right) with the lower PIB shows the higher similarity in preC/PCC. $B$, The number of correct answers to working memory task was correlated positively with the similarity index between MFG/vACC and $\operatorname{preC} / \mathrm{PCC}(\rho=0.646, p=0.0031)$.

Table 3. Brain regions with significant ${ }^{a}$ relationships between $\left[{ }^{11} \mathrm{C}\right]$ PIB-SUVR or $\left[{ }^{18} \mathrm{~F}\right] \mathrm{FDG}$-SUVR and hemodynamic similarity index

\begin{tabular}{|c|c|c|c|c|c|c|c|}
\hline \multirow[b]{2}{*}{ Brain area } & \multirow[b]{2}{*}{ BA } & \multirow[b]{2}{*}{ Hemisphere } & \multicolumn{3}{|c|}{ Coordinate $^{b}$} & \multirow[b]{2}{*}{ zscore } & \multirow[b]{2}{*}{ Cluster size } \\
\hline & & & $x$ & $y$ & $z$ & & \\
\hline \multirow{3}{*}{\multicolumn{8}{|c|}{$\begin{array}{l}\text { Negative correlation between }\left[{ }^{11} \mathrm{C}\right] \text { PIB-SUVR } \\
\text { and similarity index } \\
\text { Temporal Lobe }\end{array}$}} \\
\hline & & & & & & & \\
\hline & & & & & & & \\
\hline Fusiform Gyr. & 37 & $\mathrm{R}$ & 38 & -52 & -8 & 3.64 & 161 \\
\hline \multicolumn{8}{|l|}{ Limbic Lobe } \\
\hline Cingulate Gyr. & 24 & $\mathrm{R}$ & 15 & -7 & 33 & 5.65 & 2982 \\
\hline Cingulate Gyr. & 31 & L & -20 & -36 & 33 & 5.07 & 3265 \\
\hline Parahippocampal Gyr. & 28 & L & -22 & -13 & -17 & 4.63 & 297 \\
\hline Parahippocampal Gyr. & 28 & $\mathrm{R}$ & 13 & -21 & -19 & 4.29 & 1220 \\
\hline Cingulate Gyr. & 30 & L & -27 & -65 & 12 & 3.72 & 91 \\
\hline Cingulate Gyr. & 29 & $\mathrm{R}$ & 3 & -48 & 8 & 3.57 & 62 \\
\hline \multicolumn{8}{|l|}{ Occipital Lobe } \\
\hline Cuneus & 17 & $\mathrm{R}$ & 24 & -79 & 6 & 3.54 & 118 \\
\hline \multicolumn{8}{|l|}{ Sublobar } \\
\hline Lentiform nucleus & - & L & -8 & 1 & 0 & 3.68 & 51 \\
\hline Insula & 13 & L & -43 & -7 & 15 & 3.49 & 52 \\
\hline \multicolumn{8}{|c|}{$\begin{array}{l}\text { Positive correlation between }\left[{ }^{18} \mathrm{~F}\right] \text { FDG-SUVR } \\
\text { and dissimilarity index }\end{array}$} \\
\hline \multicolumn{8}{|c|}{ Temporal Lobe } \\
\hline Middle temporal Gyr. & 19 & L & -40 & -79 & 20 & 3.54 & 33 \\
\hline \multicolumn{8}{|l|}{ Occipital Lobe } \\
\hline Middle temporal Gyr. & 19 & R & 40 & -60 & 14 & 3.60 & 65 \\
\hline Middle temporal Gyr. & 19 & L & -41 & -60 & 16 & 3.39 & 39 \\
\hline
\end{tabular}

${ }^{a}$ Statistical significance was assumed at an individual voxel level of $p<0.001$, uncorrected. ${ }^{b}$ Talairach and Tournoux brain atlas coordinates: $x=$ distance in millimeters to the right ( + ) or left $(-)$ side of the midline; $y=$ distance anterior $(+)$ or posterior $(-)$ to the anterior commissure; $z=$ distance superior $(+)$ or inferior $(-)$ to a horizontal plane through the anterior and posterior commissures. BA, Brodmann's area; Gyr., gyrus.

index $(U=48.5, p>0.05)$, and working memory performance $(U=39.5, p>0.05)$.

\section{Discussion}

\section{Hemodynamic response, similarity index, and}

$\left[{ }^{11} \mathrm{C}\right]$ PIB uptake

Our hemodynamic study focusing on the four loci showed two opposing hemodynamic responses; i.e., DLPFC and parietal cortex were activated during cognitive tasks, while MFG/vACC and preC/PCC were deactivated (Fig. 2). This disparity was replicated by other tasks in previous studies (Raichle, 1998; Mazoyer et al., 2001; Simpson et al., 2001a; Buckner et al., 2005; Fox et al., 2005). These hemodynamic responses were shown to disappear under pathological conditions, such as mild cognitive impairment (MCI) and AD (Lustig et al., 2003; Petrella et al., 2007), suggest- ing disruption of brain default mode. Indeed, it was of particular interest that the anatomical pattern of high $\mathrm{A} \beta$ deposits in the $\mathrm{AD}$ brain was very similar to the anatomical pattern of the default mode activity, especially in the medial posterior part of the brain preC/PCC (Buckner et al., 2005). Even in nondemented elderly individuals, high levels of $\mathrm{A} \beta$ deposits were shown to be related to altered DMN activity on functional magnetic resonance imaging (fMRI) (Sperling et al., 2009). In addition, we found that the similarity index between MFG/vACC and preC/PCC across the rest and task conditions was negatively correlated with PIBSUVR (Fig. $4 A, B$ ) and positively correlated with the working memory performance (Fig. $3 B$ ). These results suggest that $A \beta$ deposition, if any, during normal aging could affect DMN activity and deteriorate cognitive performance. As shown in Table 2 


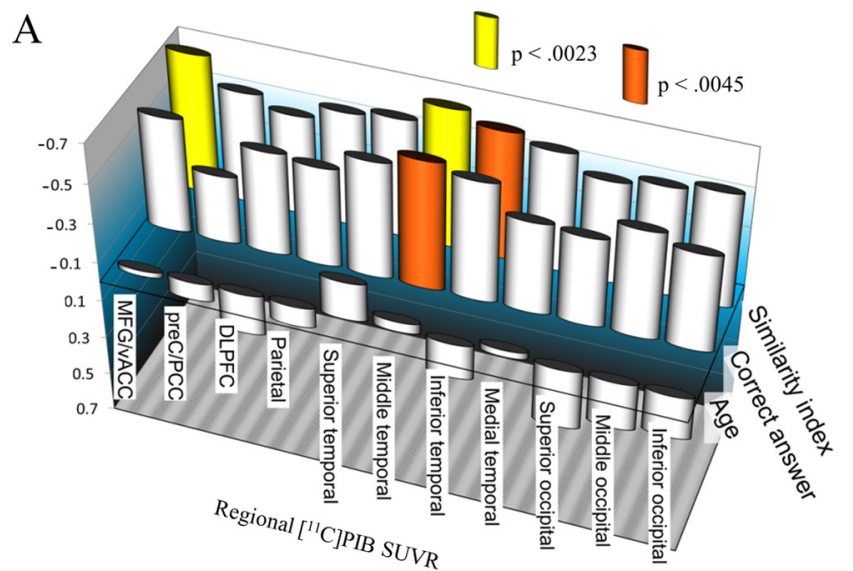

B Similarity-negative PIB regions
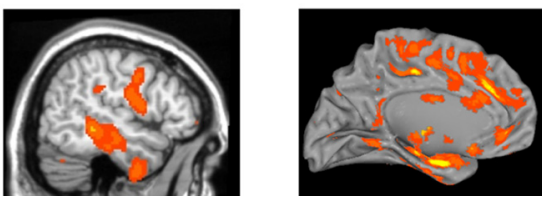

$\mathrm{T}$ value

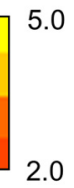

Figure 4. A, Spearman's rank correlation coefficient between adjusted regional [ $\left.{ }^{11} \mathrm{C}\right] \mathrm{PIB}-$ SUVR and hemodynamic similarity index, cognitive performance (the number of correct answers), or age. $\boldsymbol{B}$, Exploratory SPM analyses. [ $\left.{ }^{11} \mathrm{C}\right] \mathrm{PIB}-$ SUVR in the MFG, cingulate gyrus, and temporal lobes showed negatively correlations with the similarity index.

A

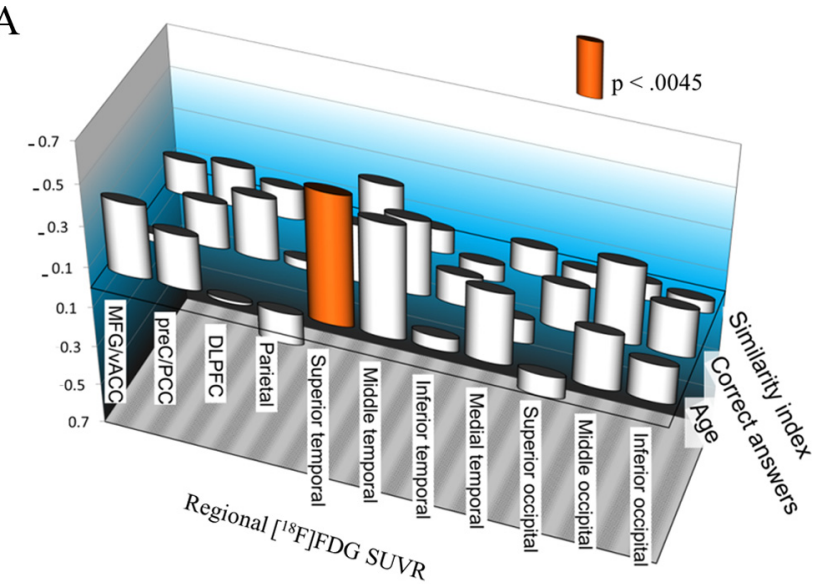

B

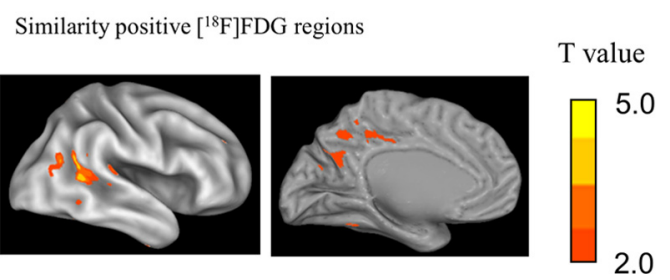

Figure 5. A, Spearman's rank correlation coefficient between adjusted regional [ $\left.{ }^{18} \mathrm{~F}\right] \mathrm{FDG}$ SUVR and hemodynamic similarity index, cognitive performance (the number of correct answers), or age. $\boldsymbol{B}$, Exploratory SPM analyses. [ ${ }^{18} \mathrm{~F}$ ]FDG-SUVR in the temporooccipital regions was positively correlated with the similarity index.

and Figures 4 and 5, effects of age and gender were negligible in this study, suggesting again that $\mathrm{A} \beta$ deposition is of a pathophysiological value for the DMN malfunction. However, to answer why women suffer more from $\mathrm{AD}$ than men (Jorm and Jolley, 1998; Fratiglioni et al., 2000), a larger number of participants with a broader age range would be necessary for clarification of gender effect.
The steady state of the brain

Imaging of a physiological baseline state of the brain depends on the imaging modality used, such as PET or MRI. PET is insensitive to second time scale fluctuations in brain physiology, but it can capture the steady state of the brain perfusion and metabolism as a stable unit parameter (Raichle et al., 1983; Ouchi et al., 2001). Considering the role of regional engagement of the basal brain function, depiction of the steady state in the target brain region may sometimes be preferable. In particular, physiological noise, such as respiratory or cardiac noise, can reduce power or yield artifactual correlations in functional connectivity studies (Lowe et al., 1998; Raj et al., 2001; Birn et al., 2006; Lund et al., 2006), and these noise sources would become artifacts that affect DMN (Birn et al., 2006). The 1 min scan of the steady state used in the present study minimized the chances of physiological artificial noise or mental unsteadiness noise. The similarity index, therefore, reflects the steady-state conditions of the brain activity (i.e., resting and working memory conditions). Although the physiological significance may be different from the fMRI methods that have been reported in previous studies (Hampson et al., 2006; Sheline et al., 2010), our results using a similarity index were consistent with those of recent fMRI studies as follows. Performance on the working memory task was positively correlated with the strength of the functional connectivity between the PCC and MFG/vACC in nine healthy subjects (Hampson et al., 2006), and higher functional connectivity between preC and anterior cingulate was observed in nondemented participants with $\left[{ }^{11} \mathrm{C}\right] \mathrm{PIB}$ negative to a certain threshold (Sheline et al., 2010). In addition, we found that $\mathrm{A} \beta$ deposits altered the brain regional engagement between preC/PCC and MFG/vACC even in nondemented elderly in a deposit-dependent manner.

\section{Similarity index in DMN}

The concept of a similarity index originates from recent studies regarding preC/PCC and MFG/vACC (Vogt et al., 1992; Bechara et al., 1997; Simpson et al., 2001a,b; Oshio et al., 2010). A fundamental dichotomy was reported between the functions of MFG/ vACC and preC/PCC (Vogt et al., 1992), in which the preC/PCC subserves evaluative functions, such as monitoring sensory events in spatial orientation and memory (Vogt et al., 1992; Oshio et al., 2010), and the MFG/vACC subserves primarily executive functions for emotional control (Bechara et al., 1997; Simpson et al., 2001a,b). When an individual is awake and alert and yet not actively engaged in an attention-demanding task (i.e., default mode), brain activities in preC/PCC and MFG/vACC would predominate in gathering and evaluating information broadly arising in the external and internal milieu (Simpson et al., 2001a). Once focused attention is required, brain activity within these areas may be attenuated. This attenuation in activity reflects a necessary reduction in resources devoted to general information collection and evaluation. Thus, neural engagement between preC/PCC and MFG/vACC would enhance the flexible reallocation of attentional resources, which may be crucial to perform cognitive tasks. As shown in the present study, this functional coupling of medial frontoposterior DMN seems to be disrupted by $\mathrm{A} \beta$ deposition in DMN along with deterioration of cognitive performance.

$\left[{ }^{11} \mathrm{C}\right] \mathrm{PIB}$ accumulation in the nondemented elderly subjects Our results confirmed that $\left[{ }^{11} \mathrm{C}\right] \mathrm{PIB}$ uptake can be a biological marker for brain functional deterioration during the preclinical state of amyloid pathology. This preclinical significance of $\left[{ }^{11} \mathrm{C}\right] \mathrm{PIB}$ uptake cannot be recognized after development of de- 
mentia in previous studies. Total amyloid level did not correlate with disease progression in histologically proven $\mathrm{AD}$ patients (Lue et al., 1999; McLean et al., 1999), and in clinically diagnosed $\mathrm{AD}$ patients, there was no significant association between $\left[{ }^{11} \mathrm{C}\right] \mathrm{PIB}$ uptake and cognitive deterioration or clinical severity (Rowe et al., 2007; Yokokura et al., 2011), or only a weak association (Pike et al., 2007). This $\left[{ }^{11} \mathrm{C}\right] \mathrm{PIB}$ accumulation seemed to reach a plateau at the level of dementia with moderate clinical severity (i.e., sum of the individual ratings of CDR >5) (Grimmer et al., 2009). In addition, recent studies also showed that $\left[{ }^{11} \mathrm{C}\right] \mathrm{PIB}$ uptake affected cognitive performance in normal aging (Pike et al., 2007; Mormino et al., 2009; Rentz et al., 2010). These lines of evidence confirm that $\left[{ }^{11} \mathrm{C}\right] \mathrm{PIB}$ uptake can be used as a surrogate marker for reduced cognitive reserve during the preclinical state of amyloid pathology. In this pathology, one of the amyloid species (soluble oligomers) is considered to be a more powerful pathogen than the insoluble amyloid fibrils in $\mathrm{AD}$ (Montalto et al., 2007). In human studies, increased soluble A $\beta$ levels in the $\mathrm{AD}$ cerebral cortices were highly correlated with disease severity (Lue et al., 1999; McLean et al., 1999). As $\left[{ }^{11} \mathrm{C}\right] \mathrm{PIB}$ cannot distinguish insoluble from soluble $\mathrm{A} \beta$ (Klunk et al., 2004), we do not currently know how much soluble $\mathrm{A} \beta$ does harm to the brain in vivo directly. However, the present observations may support the suggestion that soluble $\mathrm{A} \beta$ (oligomer) depicted partly by $\left[{ }^{11} \mathrm{C}\right] \mathrm{PIB}$ plays a central role in cognitive deterioration in the elderly. A specific probe for soluble oligomers would be desirable to gain a further understanding of its role in normal brain aging and in subjects with preclinical AD.

\section{Hemodynamic features and glucose metabolism in DMN}

In the present study, resting glucose metabolism in DMN failed to show significant correlation with hemodynamic similarity index in DMN or performance of working memory (Fig. 5A). However, exploratory SPM analysis of $\left[{ }^{18} \mathrm{~F}\right] \mathrm{FDG}$ images showed a positive correlation between hemodynamic similarity index and glucose metabolism in the temporooccipital region (Fig. 5B), which is also considered part of the lateral DMN (Fox et al., 2005; Raichle and Snyder, 2007). It is generally acknowledged that low glucose metabolism in this region is likely associated with future cognitive decline in normal subjects (Jagust et al., 2006). Thus, glucose metabolism measured by $\left[{ }^{18} \mathrm{~F}\right] \mathrm{FDG}$-PET in the lateral cortex of the brain may be involved in deterioration of taskinduced brain functions in aging. It was recently reported that unlike $\left[{ }^{18} \mathrm{~F}\right] \mathrm{FDG}$-based glucose metabolism reflecting anaerobic glycolysis, aerobic glycolysis in DMN is highlighted in preclinical $\mathrm{A} \beta$ deposition (Vlassenko et al., 2010). Indeed, our results were consistent with their suggestion because $\left[{ }^{18} \mathrm{~F}\right] \mathrm{FDG}-\mathrm{SUVR}$ reduction in preC/PCC and MFG/vACC was not significantly associated with DMN dysfunction. As the results of Vlassenko et al. (2010) were obtained by comparing different sets of groups, further studies are needed to confirm this by focusing on changes in aerobic glycolysis in DMN and brain hemodynamic discordance in the same group of nondemented elderly people. Age-related reduction of $\left[{ }^{18} \mathrm{~F}\right] \mathrm{FDG}$ in the superior temporal cortex (Fig. 5) in the present study might reflect the morphological changes because [18F]FDG-SUVR of the bilateral perisylvian areas decreased with age (Yanase et al., 2005).

\section{Conclusion}

Here we show for the first time that $\mathrm{A} \beta$ deposition in the brain of the healthy elderly is linked to a pathophysiological mechanism of impaired neuronal connectivity in DMN and the resultant decline of working memory.

\section{References}

Bechara A, Damasio H, Tranel D, Damasio AR (1997) Deciding advantageously before knowing the advantageous strategy. Science 275:12931295.

Birn RM, Diamond JB, Smith MA, Bandettini PA (2006) Separating respiratory-variation-related fluctuations from neuronal-activity-related fluctuations in fMRI. Neuroimage 31:1536-1548.

Brett M, Anton JL, Valabregue R, Poline JB (2002) Region of interest analysis using an SPM toolbox [abstract]. Paper presented at the 8th International Conference on Functional Mapping of the Human Brain, Sendai, Japan.

Buckner RL, Snyder AZ, Shannon BJ, LaRossa G, Sachs R, Fotenos AF, Sheline YI, Klunk WE, Mathis CA, Morris JC, Mintun MA (2005) Molecular, structural, and functional characterization of Alzheimer's disease: evidence for a relationship between default activity, amyloid, and memory. J Neurosci 25:7709-7717.

Cabeza R, Nyberg L (2000) Imaging cognition II: an empirical review of 275 PET and fMRI studies. J Cogn Neurosci 12:1-47.

Drzezga A, Lautenschlager N, Siebner H, Riemenschneider M, Willoch F, Minoshima S, Schwaiger M, Kurz A (2003) Cerebral metabolic changes accompanying conversion of mild cognitive impairment into Alzheimer's disease: a PET follow-up study. Eur J Nucl Med Mol Imaging 30:1104-1113.

Dubois B, Slachevsky A, Litvan I, Pillon B (2000) The FAB: a Frontal Assessment Battery at bedside. Neurology 55:1621-1626.

Fox MD, Snyder AZ, Vincent JL, Corbetta M, Van Essen DC, Raichle ME (2005) The human brain is intrinsically organized into dynamic, anticorrelated functional networks. Proc Natl Acad Sci U S A 102:9673-9678.

Fratiglioni L, Launer LJ, Andersen K, Breteler MM, Copeland JR, Dartigues JF, Lobo A, Martinez-Lage J, Soininen H, Hofman A (2000) Incidence of dementia and major subtypes in Europe: a collaborative study of population-based cohorts. Neurologic Diseases in the Elderly Research Group. Neurology 54:S10-S15.

Greicius MD, Krasnow B, Reiss AL, Menon V (2003) Functional connectivity in the resting brain: a network analysis of the default mode hypothesis. Proc Natl Acad Sci U S A 100:253-258.

Greicius MD, Srivastava G, Reiss AL, Menon V (2004) Default-mode network activity distinguishes Alzheimer's disease from healthy aging: evidence from functional MRI. Proc Natl Acad Sci U S A 101:4637-4642.

Grimmer T, Henriksen G, Wester HJ, Förstl H, Klunk WE, Mathis CA, Kurz A, Drzezga A (2009) Clinical severity of Alzheimer's disease is associated with PIB uptake in PET. Neurobiol Aging 30:1902-1909.

Gusnard DA, Raichle ME (2001) Searching for a baseline: functional imaging and the resting human brain. Nat Rev Neurosci 2:685-694.

Hampson M, Driesen NR, Skudlarski P, Gore JC, Constable RT (2006) Brain connectivity related to working memory performance. J Neurosci 26:13338-13343.

Hedden T, Van Dijk KR, Becker JA, Mehta A, Sperling RA, Johnson KA, Buckner RL (2009) Disruption of functional connectivity in clinically normal older adults harboring amyloid burden. J Neurosci 29:12686-12694.

Herscovitch P, Markham J, Raichle ME (1983) Brain blood flow measured with intravenous H2(15)O. I. Theory and error analysis. J Nucl Med 24:782-789.

Jagust W, Gitcho A, Sun F, Kuczynski B, Mungas D, Haan M (2006) Brain imaging evidence of preclinical Alzheimer's disease in normal aging. Ann Neurol 59:673-681.

Jorm AF, Jolley D (1998) The incidence of dementia: a meta-analysis. Neurology 51:728-733.

Klunk WE, Engler H, Nordberg A, Wang Y, Blomqvist G, Holt DP, Bergström M, Savitcheva I, Huang GF, Estrada S, Ausén B, Debnath ML, Barletta J, Price JC, Sandell J, Lopresti BJ, Wall A, Koivisto P, Antoni G, Mathis CA, et al. (2004) Imaging brain amyloid in Alzheimer's disease with Pittsburgh Compound-B. Ann Neurol 55:306-319.

Lowe MJ, Mock BJ, Sorenson JA (1998) Functional connectivity in single and multislice echoplanar imaging using resting-state fluctuations. Neuroimage 7:119-132.

Lue LF, Kuo YM, Roher AE, Brachova L, Shen Y, Sue L, Beach T, Kurth JH, Rydel RE, Rogers J (1999) Soluble amyloid beta peptide concentration as a predictor of synaptic change in Alzheimer's disease. Am J Pathol 155:853-862. 
Lund TE, Madsen KH, Sidaros K, Luo WL, Nichols TE (2006) Non-white noise in fMRI: does modelling have an impact? Neuroimage 29:54-66.

Lustig C, Snyder AZ, Bhakta M, O’Brien KC, McAvoy M, Raichle ME, Morris JC, Buckner RL (2003) Functional deactivations: change with age and dementia of the Alzheimer type. Proc Natl Acad Sci US A 100: 14504-14509.

Maeshima S, Itakura T, Nakagawa M, Nakai K, Komai N (1997) Visuospatial impairment and activities of daily living in patients with Parkinson's disease: a quantitative assessment of the cube-copying task. Am J Phys Med Rehabil 76:383-388.

Mazoyer B, Zago L, Mellet E, Bricogne S, Etard O, Houdé O, Crivello F, Joliot M, Petit L, Tzourio-Mazoyer N (2001) Cortical networks for working memory and executive functions sustain the conscious resting state in man. Brain Res Bull 54:287-298.

McLean CA, Cherny RA, Fraser FW, Fuller SJ, Smith MJ, Beyreuther K, Bush AI, Masters CL (1999) Soluble pool of Abeta amyloid as a determinant of severity of neurodegeneration in Alzheimer's disease. Ann Neurol 46:860-866.

Mintun MA, Larossa GN, Sheline YI, Dence CS, Lee SY, Mach RH, Klunk WE, Mathis CA, DeKosky ST, Morris JC (2006) [11C]PIB in a nondemented population: potential antecedent marker of Alzheimer disease. Neurology 67:446-452.

Montalto MC, Farrar G, Hehir CT (2007) Fibrillar and oligomeric betaamyloid as distinct local biomarkers for Alzheimer's disease. Ann N Y Acad Sci 1097:239-258.

Mormino EC, Kluth JT, Madison CM, Rabinovici GD, Baker SL, Miller BL, Koeppe RA, Mathis CA, Weiner MW, Jagust WJ (2009) Episodic memory loss is related to hippocampal-mediated beta-amyloid deposition in elderly subjects. Brain 132:1310-1323.

Morris JC (1993) The Clinical Dementia Rating (CDR): current version and scoring rules. Neurology 43:2412-2414.

Nelissen N, Vandenbulcke M, Fannes K, Verbruggen A, Peeters R, Dupont P, Van Laere K, Bormans G, Vandenberghe R (2007) Abeta amyloid deposition in the language system and how the brain responds. Brain 130:2055-2069.

Oshio R, Tanaka S, Sadato N, Sokabe M, Hanakawa T, Honda M (2010) Differential effect of double-pulse TMS applied to dorsal premotor cortex and precuneus during internal operation of visuospatial information. Neuroimage 49:1108-1115.

Ouchi Y, Yoshikawa E, Okada H, Futatsubashi M, Sekine Y, Iyo M, Sakamoto M (1999) Alterations in binding site density of dopamine transporter in the striatum, orbitofrontal cortex, and amygdala in early Parkinson's disease: compartment analysis for beta-CFT binding with positron emission tomography. Ann Neurol 45:601-610.

Ouchi Y, Okada H, Yoshikawa E, Futatsubashi M, Nobezawa S (2001) Absolute changes in regional cerebral blood flow in association with upright posture in humans: an orthostatic PET study. J Nucl Med 42:707-712.

Ouchi Y, Kanno T, Okada H, Yoshikawa E, Shinke T, Nagasawa S, Minoda K, Doi H (2006) Changes in cerebral blood flow under the prone condition with and without massage. Neurosci Lett 407:131-135.

Ouchi Y, Yoshikawa E, Futatsubashi M, Yagi S, Ueki T, Nakamura K (2009) Altered brain serotonin transporter and associated glucose metabolism in Alzheimer disease. J Nucl Med 50:1260-1266.

Owen AM, McMillan KM, Laird AR, Bullmore E (2005) N-back working memory paradigm: a meta-analysis of normative functional neuroimaging studies. Hum Brain Mapp 25:46-59.

Petrella JR, Prince SE, Wang L, Hellegers C, Doraiswamy PM (2007) Prognostic value of posteromedial cortex deactivation in mild cognitive impairment. PLoS One 2:e1104.

Pike KE, Savage G, Villemagne VL, Ng S, Moss SA, Maruff P, Mathis CA, Klunk WE, Masters CL, Rowe CC (2007) Beta-amyloid imaging and memory in non-demented individuals: evidence for preclinical Alzheimer's disease. Brain 130:2837-2844.

Raichle ME (1998) Behind the scenes of functional brain imaging: a historical and physiological perspective. Proc Natl Acad Sci U S A 95:765-772.
Raichle ME, Snyder AZ (2007) A default mode of brain function: a brief history of an evolving idea. Neuroimage 37:1083-1090; discussion 1097-1099.

Raichle ME, Martin WR, Herscovitch P, Mintun MA, Markham J (1983) Brain blood flow measured with intravenous H2(15)O. II. Implementation and validation. J Nucl Med 24:790-798.

Raj D, Anderson AW, Gore JC (2001) Respiratory effects in human functional magnetic resonance imaging due to bulk susceptibility changes. Phys Med Biol 46:3331-3340.

Reisberg B (1986) Dementia: a systematic approach to identifying reversible causes. Geriatrics 41:30-46.

Rentz DM, Locascio JJ, Becker JA, Moran EK, Eng E, Buckner RL, Sperling RA, Johnson KA (2010) Cognition, reserve, and amyloid deposition in normal aging. Ann Neurol 67:353-364.

Rowe CC, Ng S, Ackermann U, Gong SJ, Pike K, Savage G, Cowie TF, Dickinson KL, Maruff P, Darby D, Smith C, Woodward M, Merory J, TochonDanguy H, O’Keefe G, Klunk WE, Mathis CA, Price JC, Masters CL, Villemagne VL (2007) Imaging beta-amyloid burden in aging and dementia. Neurology 68:1718-1725.

Sheline YI, Raichle ME, Snyder AZ, Morris JC, Head D, Wang S, Mintun MA (2010) Amyloid plaques disrupt resting state default mode network connectivity in cognitively normal elderly. Biol Psychiatry 67:584-587.

Silverman DH, Small GW, Chang CY, Lu CS, Kung De Aburto MA, Chen W, Czernin J, Rapoport SI, Pietrini P, Alexander GE, Schapiro MB, Jagust WJ, Hoffman JM, Welsh-Bohmer KA, Alavi A, Clark CM, Salmon E, de Leon MJ, Mielke R, Cummings JL, et al. (2001) Positron emission tomography in evaluation of dementia: regional brain metabolism and long-term outcome. JAMA 286:2120-2127.

Simpson JR Jr, Snyder AZ, Gusnard DA, Raichle ME (2001a) Emotioninduced changes in human medial prefrontal cortex: I. During cognitive task performance. Proc Natl Acad Sci U S A 98:683-687.

Simpson JR Jr, Drevets WC, Snyder AZ, Gusnard DA, Raichle ME (2001b) Emotion-induced changes in human medial prefrontal cortex: II. During anticipatory anxiety. Proc Natl Acad Sci U S A 98:688-693.

Sperling RA, Laviolette PS, O'Keefe K, O’Brien J, Rentz DM, Pihlajamaki M, Marshall G, Hyman BT, Selkoe DJ, Hedden T, Buckner RL, Becker JA, Johnson KA (2009) Amyloid deposition is associated with impaired default network function in older persons without dementia. Neuron 63:178-188.

Supekar K, Menon V, Rubin D, Musen M, Greicius MD (2008) Network analysis of intrinsic functional brain connectivity in Alzheimer's disease. PLoS Comput Biol 4:e1000100.

Tzourio-Mazoyer N, Landeau B, Papathanassiou D, Crivello F, Etard O, Delcroix N, Mazoyer B, Joliot M (2002) Automated anatomical labeling of activations in SPM using a macroscopic anatomical parcellation of the MNI MRI single-subject brain. Neuroimage 15:273-289.

Vlassenko AG, Vaishnavi SN, Couture L, Sacco D, Shannon BJ, Mach RH, Morris JC, Raichle ME, Mintun MA (2010) Spatial correlation between brain aerobic glycolysis and amyloid-beta (Abeta) deposition. Proc Natl Acad Sci U S A 107:17763-17767.

Vogt BA, Finch DM, Olson CR (1992) Functional heterogeneity in cingulate cortex: the anterior executive and posterior evaluative regions. Cereb Cortex 2:435-443.

Yanase D, Matsunari I, Yajima K, Chen W, Fujikawa A, Nishimura S, Matsuda H, Yamada M (2005) Brain FDG PET study of normal aging in Japanese: effect of atrophy correction. Eur J Nucl Med Mol Imaging 32:794-805.

Yokokura M, Mori N, Yagi S, Yoshikawa E, Kikuchi M, Yoshihara Y, Wakuda T, Sugihara G, Takebayashi K, Suda S, Iwata Y, Ueki T, Tsuchiya KJ, Suzuki K, Nakamura K, Ouchi Y (2011) In vivo changes in microglial activation and amyloid deposits in brain regions with hypometabolism in Alzheimer's disease. Eur J Nucl Med Mol Imaging 38:343-351.

Zhang HY, Wang SJ, Xing J, Liu B, Ma ZL, Yang M, Zhang ZJ, Teng GJ (2009) Detection of PCC functional connectivity characteristics in resting-state fMRI in mild Alzheimer's disease. Behav Brain Res 197:103-108. 